\title{
A Review of Recent Studies on Urban Stormwater Drainage System for Urban Flood Management
}

\author{
Manaye Teshome Sewnet* \\ Scholl of civil Engineering and Architecture \\ Adama Science and Technology University \\ Adama, Ethiopia \\ manaye.teshome@gmail.com
}

\author{
Allu Revathi Devi (Associate Professor) \\ HOD Architecture Department \\ Andhra University \\ Vishakhapatnam, India \\ allurevathidevi@yahoo.com
}

\begin{abstract}
Stormwater drainage and urban flooding are the popular issues in policy agendas and academia. Although the research on these title increases steadily an integrated review on stormwater drainage and urban flood with a focus on pluvial flooding has yet to be produced. This paper presents a critical review on stormwater drainage and urban flood based on 78 selected journal papers published over the period of 1990 to 2018. The review focus on pluvial flooding to relate urban stormwater drainage management and urban flood disaster management and to show the links between the two. The methods taken to manage urban stormwater drainage and urban flooding as well as the complexity of achieving a comprehensive urban flood disaster management are evaluated and discussed. To better understand the concepts behind urban flood and improve the urban flood risk management strategies, recommendation of future research directions are also provided.
\end{abstract}

Key words- stormwater drainage, urban flood, urban drainage management, food disaster management

\section{INTRODUCTION}

Urban flooding is a major catastrophic trait of many cities around the world, which is a result of manifold and uncertain factors such as, hydrological factors, urbanization, climate change and infrastructure inadequacy and failures that result in property damage, critical infrastructure distraction and loss of lives. It highly affects the local economy and overall urban environment (Morita, 2014, Mugume \& Butler, 2017; Liu, Li, Xia, Jin, \& Chen, 2016). Due to this challenges of human environment the interest in urban flood risk management is increasing (ten Veldhuis, Clemens, \& van Gelder, 2011). Generally, structural and non-structural measures are taken to best manage the urban flood risk (Lee, Lee, Joo, Jung, \& Kim, 2016; Morita, 2014).

Urban pluvial flood is occurred in urban areas due to the imbalance between stormwater drainage systems capacity and amount of rainfall and runoff intensity. To better address its damage urban drainage models are prepared to assess the relationship between extent and duration of flood and to shift from conventional drainage system to sustainable urban drainage systems (SuDS) (Torgersen, Bjerkholt, \& Lindholm, 2014, Jahanbazi \& Egger, 2014). Stormwater drainage systems are the basic components of flood risk management in urban areas, various drainage facilities can be constructed to reduce the risk. The advancement in technology and the emergence of several important software applications brings the use of better hydrological modeling to address the issue (Chen, Leandro, \& Djordjević, 2016; Lee et al., 2016; Bertsch, Glenis, \& Kilsby, 2017). In order to achieve efficient and effective urban flood risk management first, it is better to understand the factors behind it. Discussion by many other researchers are scattered in different areas with an integrating the overall concepts of stormwater drainage and urban flooding is yet to be done.

Therefore, this paper presents a critical review of recent studies on stormwater drainage and urban flood management with a special focus on pluvial flooding. It begins with the background of pluvial flooding, stormwater drainage, and urban flood management; proceeded by the research methodology and overview of the research progress. Then selected papers are discussed depending on the following features; methods to assess the risk of urban flooding, methods to reduce or illuminate the risk of pluvial flooding, the interaction between stormwater drainage and urban flooding, and evaluation of approaches taken to urban flood risk management. Lastly summary of the findings from this study and recommendations for future researches in this field included in the discussion part.

\section{BACKGROUND OF STORMWATER DRAINAGE SYSTEM AND URBAN FLOODING}

\subsection{Stormwater}

Stormwater is a rainwater with other impurities within it that might be percolate in to the ground, retained on surface and/ or runoff. In urban environment, because of imperviousness stormwater cannot easily infiltrate to the ground as it does in natural landscape this creates effects such as flooding and water pollution (Schueler, 1994). Stormwater if it is managed well and harvested it can be the most important source of fresh water. Stormwater management includes controlling its quality and quantity with structural and operational practices, an integrated water management is the essential aspect in urban environment.

\subsection{Stormwater drainage system}

Stormwater sewer, sock ways and collection in storage tanks are the basic ways of disposing rainfall. Storm drains vary in design in most cases carries storm water but in some cases carries both stormwater, and sanitary sewers (MCGM, 2005). Proper attention should be given for drainage and

\footnotetext{
*corresponding author, Tel: +251910376266
}

Email address: manaye.teshome@gmail.com 
sewerage system for preventing urban flooding. The complex increasing factors of flooding needs a change from conventional drainage system to sustainable drainage system (Torgersen, Bjerkholt, \& Lindholm, 2014). Sustainable urban drainage system (SuUDS) is an idea to minimize the effect of urbanization using natural systems that are cost effective and low impact on environment (Sharma, 2008).

\subsection{Urban flood}

According to Asfaw, (2016) in addition to urban flood and pluvial flood, flash flood, coastal flood, river flood and catastrophic flood are other flood types cause several disasters to the environment. Urban flood is inundation of properties and dry land of densely built up environment when the urban drainage and sewage system capacity cannot handle the stormwater from extreme rainfall. Even though there are many hydrological and metrological factors for urban flood, inadequacy or design problems of drainage system is the basic cause for urban flooding. It exacerbated by the large impervious surface of urban areas, the pavement of streets and roads decrease infiltration and increase the flow speed that make the flood more dangerous. Urban flood is high disturbance of the urban environment that have high economic damages but limited causalities because it raises slowly and its level is mostly low.

\subsection{Urban Pluvial flood}

Pluvial flood is urban flood when the capacity of urban drainage systems cannot handle the stormwater from extreme rainfall. It negatively affects urban environment in many ways. To address it well there is a need to shift from old urban drainage system to sustainable urban drainage system through an assessment of drainage behaviors using urban drainage models (Jahanbazi \& Egger, 2014; Torgersen et al., 2014)

\subsection{Urban flood management}

There are structural and nonstructural measures taken to mitigate flood risk. For any of the mitigation measures quantifying the risk of flood is essential to apply specific solution. There are six major flood disaster management steps. These are flood-forecasting, reduction of runoff, reducing flood peak by volume reduction, reducing flood levels, protection against inundation and flood peak zoning (Morita, 2014). Urban flood management needs a change from emergency response to preparedness planning as now is recognized.

The most important elements of flood disaster management are identified, According to Nation, (2002) risk management and flood plain delineation, the use of supportive technologies, flood plain management, watershed management, climate variability and change, development of strategies and plans, and emergency preparedness and response are the key points.

\subsection{Urban Drainage Models}

Urban flood is complex to manage due to its dynamic nature and the use of computer and numerical models with software tools become mandatory to draw flow forecast and vulnerability analysis of flood risks (Pathirana, Tsegaye, Gersonius, \& Vairavamoorthy, 2011). Supportive technologies such as GIS, Mapping and visualization techniques are essential elements supporting the overall management of urban flooding. As Pathirana et al., (2011) states that selection of the less complex and cost effective inundation modeling technique is essential but not easy.

As stated by Gilles \& Moore, (2010), Hydraulic modeling is essential element in forecasting flood events and used to properly manage flood risk. There are one-dimensional numeric (1-D) model and two-dimensional numeric (2-D) models used in conjunction with several commercial and noncommercial software. Due to its simplicity, 1-D model was used commonly but it is difficult to address the complex interaction between different hydraulic systems this leads to the use of 2-D models. Even though 2-D models are much better than 1-D models, it is difficult to model structural elements in 2-D modeling. Therefore coupling of 1-D and 2-D models become preferable to achieve better results. It is become common research topic to couple 1-D and 2-D drainage network models along with the use of several modeling software such as the commonly used SWMM to get a better result. As stated under Rossman, (2015) SWMM is a powerful application software used for planning, analyzing and designing of urban stormwater drainage developed by united state environmental protection agency (EPA). It is essential to develop integrated models used to assess the storm quality and quantity.

Stakeholder including government bodies and public collaboration and cooperation is essential to address the complex flood risk even if it is challenging to organize different parties. It is challenging because it need first to define what, why and how to participate different stakeholders to gain the optimal effect (Evers, 2012).

In whatever the scenario and techniques urban stormwater drainage system management is mandatory to solve the challenging problem of urban flooding. A complete integrated analysis and management with of stormwater, urban drainage systems and urban flooding with a clear representation of their relation is required.

\section{METHODOLOGY}

\subsection{Paper Retrieval}

Stormwater can also be written as storm water and in some case only storm though stormwater drainage, storm water drainage or storm drains have similar meaning, similarly, flood disaster management and flood risk management are used interchangeably. Therefore, the key words used to search the literatures were stormwater drainage (storm water drainage), storm drain, urban water, flood, flood disaster management and flood risk management. The search rule used was ("stormwater" OR "storm water" OR "drainage" OR "storm drain" OR "urban water") AND ("flood" OR "flooding" OR "disaster management" OR "risk management") aiming to gate papers titled with a combination of stormwater drainage and flood disaster/risk management. The search rule was put in the SCI database with Title as search criteria. The search criteria title was selected to select more relevant papers as the field of study had numerous amount of papers, for example, if it is

\footnotetext{
*corresponding author, Tel: +251910376266

Email address: manaye.teshome@gmail.com
} 
topic more than 4,475 results are obtained as the date of 2018/03/10.

The following procedure generally adopted for retrieving the papers.

i). With the above search rule title was scanned in the SCI database with the time span of 1989/08/01 to 2018/03/10 with the language of English. Through this scan, 154 papers were found including articles, reviews, editorial materials and proceedings papers.

ii). 145 Articles were selected excluding editorial materials and proceedings papers.

iii). The abstract of each paper was read to select relevant ones. Then, 86 papers were selected and ten papers were filtered out and excluded with detail study of their content. Finally, 78 papers were selected for the literature review.

\subsection{Overview of selected papers}

A general Analysis was made on the selected 86 papers to find out the research interest on the storm water drainage and flood with the selected time span (Figure1) and to find out the distribution of papers in different journals (Table 1).

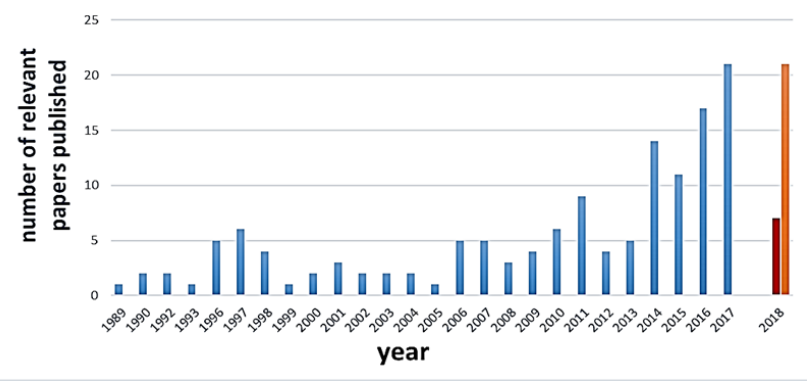

Figure 1. relevant paper published in the selected journals

TABLE I. DISTRIBUTION OF THE REVIEWED PAPERS ACCORDING TO SOURCE

\begin{tabular}{lc}
\hline & NO. \\
JOURNAL TITLE & SELECTED \\
& PAPERS IN \\
& THE \\
JOURNAL \\
\hline
\end{tabular}

Advances in Water Resources

2

Canadian Journal of Civil Engineering

Chinese Science Bulletin

Clean - Soil, Air, Water

Computers and Geosciences

Earth Surface Processes and Landforms

Ecological Economics journal

Ecological Engineering

Ecology and Society

Environmental Geology

Environmental History

Environmental Management

Environmental Modelling and Software
Environmental Science and Policy

Frontiers of Environmental Science and Engineering

GeoInformatica

Hydraulic engineering

Hydrological Processes

Hydrological Sciences Journal

Hydrology and Earth System Sciences

International Journal for Numerical Methods in Fluids

International Journal of Disaster Recovery and Business Continuity

International Journal of Earth Sciences and Engineering

International Journal of Engineering Development and

Research

Irrigation and Drainage

JAWRA Journal of the American Water ...

Journal of Cleaner Production

Journal of Environmental Management

Journal of Flood Risk Management

Journal of Geophysical Research F: Earth Surface

Journal of Hydro-Environment Research

Journal of Hydrologic Engineering

Journal of Hydrology

Journal of Hydrology: Regional Studies

Journal of Network and Computer Applications

Journal of Soil and Water Conservation

Journal of Water Resources Planning and Management

Land Degradation and Development

Monthly Weather Review

Natural Hazards

Philosophical Transactions of the Royal Society A:

Mathematical, Physical and Engineering Sciences

Proceedings of the Institution of Civil Engineers - Urban

Design and Planning

Proceedings of the Institution of Civil Engineers - Water Management

Structure and Infrastructure Engineering

Transportation Research Part D: Transport and

Environment

Urban Water Journal

Water

Water (Switzerland)

Water Policy

Water Resources Management

Water Resources Research

Water Science and Technology

Water Science and Technology

TOTAL

*corresponding author, Tel: +251910376266

Email address: manaye.teshome@gmail.com 


\section{REVIEW OF STUDIES ON STORMWATER DRAINAGE FOR URBAN FLOOD MANAGEMENT:}

Urban flooding in many research papers related to urbanization in addition to other manifold factors. In most of the papers urbanization is related to overstressing of urban drainage systems and increased imperviousness. According to Rjeily, Abbas, Sadek, Shahrour, \& Chehade (2017); Jahanbazi \& Egger (2014); Mugume \& Butler (2017); Liu et al. (2016); Underwood (2006); Nguyen et al. (2017), urban drainage systems are overstressed and unable to handle the increased runoff volume due to activities related to urbanization and hydrological factors raised from climate change in addition to aging and structural failure. Drainage infrastructures are not upgraded when cities are expanded which is the main reason for overstressing of urban drainage system. As Batica (2015) states, Flood in urban areas become a common and frequent phenomenon. The increase in impervious surfaces and intensity of rainfall imposes great pressure on urban drainage systems.

Most of studies states the consequences of urban flooding in a broader sense. A serious of studies states that urban flooding results in loss of lives, property damage and infrastructure distraction (Jahanbazi \& Egger, 2014; Mugume \& Butler, 2017; Liu et al., 2016). Flood damage assessment is one of the critical issue in studies related to urban flooding. To minimize the risk caused by urban flooding an effective urban flood management strategy is essential. Several concepts in different studies are dealt regarding to urban flood management.

Studies related to urban flooding covers a wide range of topics, many of them are overlapped and thus cannot easily classified in to certain filed. To gate a better understanding of the research area and to identify the possible gaps in the knowledge base, this paper examine the findings of the studies based on the following structure: 1) urban stormwater management; 2) urban drainage management; 3) urban flood disaster management; 4) Assessment of flood resilience and flood risk management strategies; 5) flood and stormwater drainage models. The first part focused on activities involving technical and institutional aspects for controlling and quantifying runoff. It is basic for the functioning of urban environment through mitigating the effects of stormwater such as flooding. The second part deals about creating sustainable urban drainage systems. Sustainable urban drainage system aim to reduce the potential impacts of surface water runoff through reducing the peak flows and stormwater treatment using natural ways. This involves design of drainage systems, identifying the appropriate type of drainages to the intended function, material selection for construction of drainage systems, proper alignment of drainage structures, understanding hydraulics of drainage structure, selection of appropriate method for hydraulic analysis and the use of appropriate models to better understand the urban drainage scenario. The third one is a wider topic that is linked to many urban aspects that aim to minimize damages caused by urban flooding. It generally focused on controlling of the intensity, volume and speed of runoff water flow with structural and nonstructural measures. Figure 2 shows the key elements in urban flood disaster management. The fourth part focuses on flood resilience and urban system, resilience and urban flood risk management, methodology for assessing flood risk management, and flood resilience assessment. Adding resilience concept to flood risk management helps to create urban environment which have ability to accept, resist, recover and learn from the flooding events (Batica, 2015). The final part covers the hydrologic and hydraulic modeling. Urban flood is dynamic and complex to manage thus the use of appropriate tools is mandatory. To better understand and solve the increasing risk of flooding and drainage problems the use of numerical models and computer technologies is vital. It involves the use of $1 \mathrm{D}, 2 \mathrm{D}$ and coupling of 1D/2D models and software such as the commonly used SWMM.

\section{Key Elements of Flood Disaster Management}

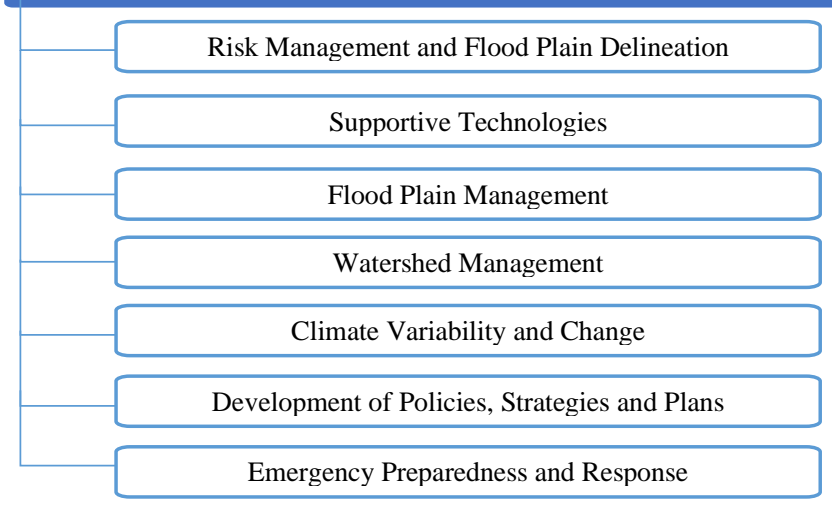

Figure 2. key elements of flood disaster management

\subsection{Stormwater Management}

\subsubsection{Urban Stormwater Management}

An activity involves technical and institutional aspects for controlling quality and quantity of runoff is called stormwater management (Nanía, Leon, \& García, 2014; PNRCDC, 2014). Guo \& Zhuge (2008) indicates estimation of Runoff volume frequency distribution and peak discharge rate as one of the task in urban stormwater management. Petit-Boix et al. (2015) states that stormwater management plays major role in preventing flood. As stated by PNRCDC (2014), urban Stormwater management helps to manage the problems arise from imperviousness of urban areas such as decreasing in ground water recharge, high frequency of flooding, instability of stream channels and damage to infrastructures. Stormwater management also have economic benefits by reducing the maintenance and cleaning cost of stormwater drainage systems and increasing their lifetime.

Stormwater management is complex in nature but because it is basic for the functioning of urban environment, it gains much attention and evolving overtime (Jiang, Zevenbergen, \& Ma, 2018). Because of its complexity different methodologies, approaches and techniques are observed in the reviewed studies and as Guo \& Zhuge (2008) points the use of hydrological models specifically designed for stormwater management purpose called stormwater models become common.

In stormwater management following environmentally safe and nature friendly measures is essential. Lamond, Rose, \&

*corresponding author, Tel: +251910376266

Email address: manaye.teshome@gmail.com 
Booth (2015) states that measures that are designed to restore or resemble the natural infiltration patter have a great role in reduction of runoff volume and regulate peak flows thus can reduce flooding problems in urban areas. The term used in natural friendly stormwater management approaches vary in respect to countries, context and time but with similar design philosophies. Some of the terms are best management practices (BMPs), sustainable drainage system (SuDS), surface water management models (SWMMs), storm control measures (SCMs), low impact development (LID), water sensitive urban design (WSUD) and green infrastructure (Lamond, Rose, \& Booth, 2015; Q. Zhou, 2014; Elliott \& Trowsdale, 2007).

\subsubsection{Stormwater Best management practice (BMP)}

Best management practice (BMP) is a term used for structural and engineering measure of stormwater management which have a paramount importance in preventing flood in urban areas. Sharma (2008) states that $\mathrm{SuDS}$ (BMP) is management technique mainly for surface water through the use of natural drainage in conjunction with technologies and policies. BMPs used to reduce or prevent stormwater negative effects through structural, vegetative or managerial practices. Structural practices involves the construction of stormwater management facilities, vegetative practices includes several landscaping practices and managerial practices encompasses the pollution prevention techniques. The common BNMPs or SUDS includes filter strips, filter drains, infiltration basin, infiltration trenches, permeable surface, gravel wet land, porous pavements, bio-retention, wet pond and dry detention pond, water storage, swales and stormwater harvesting (Q. Zhou, 2014; Elliott \& Trowsdale, 2007; Sharma, 2008; Petit-Boix et al., 2017; Bahri, 2012).

The application of SuDS is increasing to solve the challenges of climate change and urbanization on urban drainage facilities. SuDS have a positive effect on nature and environment (Q. Zhou, 2014; Elliott \& Trowsdale, 2007). Zhou (2007) emphasizes BMPs are the most effective way to control flood, maintain stability of the site and improve water quality. Zhou (2007) points the control of runoff before it reaches to a sink hole is the effective way to control flood in BMP. According to Zhou (2007) study, there are three major functions of BMP in relation to water quantity. 1) Increase storage; 2) Reduce recharge rate and 3) Enhance the discharge capacity. Tahmasebi Birgani \& Yazdandoost (2014) assess the performance of urban drainage measures including three best management practices (BMPs) namely Green roof, pervious pavements and detention ponds by adding them in to the existing urban drainage system in the study area of Tehran-Iran and observing the improvements of the persistence of urban drainage risk management system (UDRM). According to a result of Tahmasebi Birgani \& Yazdandoost (2014) study the BMPs significantly increase the UDRM system thus plays significant role in reduction of urban flood. Sharma (2008) discuss the importance of sustainable drainage system or BMPs in managing stormwater and to combat diffuse pollution. Sharma (2008) states SuDS or BMPs are cost effective solutions, easily managed and resilient in use but the implementation of these techniques demands involvement of various stakeholders and must be evaluate by certain criteria placed by decision support system (DSS).

According to Petit-Boix et al. (2017), Best management practice (BMP) are divided in to two gray and green where gray is the use of traditional infrastructure such as sewers and detention tanks whereas green provides ecosystem services such as aquifer recharge or environmental restoration. PetitBoix et al. (2017) probed the importance of green and gray stormwater management infrastructures such as the filter, swale and infiltration trench (FST) for preventing flood. Petit-Boix et al. (2015) study filter, swell and infiltration trench (FST) one of stormwater BMP built in São Carlos (Brazil) to determine its environmental and economic impacts. In this study they observed FST prevented $95 \%$ of the areas runoff and proved FST is a good solution in comparison to PVC stormwater pipes as well reduces economic and environmental impacts and increase the life span of the drainage system. Green-blue stormwater management solutions are the effective sustainable stormwater solution to low impact development and there implementation is increasing around the world. Blue-green stormwater control measures bring natural water management and green infrastructure together. Haghighatafshar et al. (2018) study the flood mitigation efficiency of blue-green stormwater management techniques by using $1 \mathrm{D}$ sewer and 2D overland flow models and conclude that they are effective in controlling local flooding.

In urbanized city where there is no space available for developing new drainage pattern like the study of Sharma (2008) in Delhi-India, integrated approach that is developing the SuDS along with the existing one is mandatory. Morsy, Goodall, Shatnawi, \& Meadows (2016) mention that to address flooding problems in highly urbanized areas where there is a limitation of space, distributed low impact development (LID) stormwater control method is highly effective (Morsy et al., 2016). Lamond et al. (2015) concluded that SuDS is important emerging concept in modern urban design but its implementation in dense urban areas is difficult because problems related to access for installation and maintenance, ownership of buildings and urban spaces, luck of subsurface space and aesthetic. The other factor that affect the implementation of SuDS is policy and governance. As an example Jiang, Zevenbergen, \& Fu, (2017) studies the difficulties to implement SuDS in china and states that the growing water problem and urban flooding frequency pushes china to develop a new policy initiative called sponge cities which an integrated SuSD approach but its implementation is hindered by governance capacity, luck of knowledge and experience. Therefore SuDS should be seen as a part of integrated solution and an integrated approach.

The application and concept of SUDS/ BMPs is showing advancement due to time. Q. Zhou (2014) review the development and application of SUDS by assessing their design criteria, techniques and models and tools used in simulation and analysis. Q. Zhou (2014) points that serving as a cleaning mechanism and protecting flood was the previous aim of SUDS whereas in recent years environmental protection and beatification are added to the previous aims. In current trained SUDS should integrate water quality, water quantity,

\footnotetext{
*corresponding author, Tel: +251910376266

Email address: manaye.teshome@gmail.com
} 
biodiversity, amenity, public health and hygienic conditions of urban areas (Q. Zhou, 2014).

\subsubsection{Stormwater harvesting}

It is the process of collecting, storing, treating and distributing of stormwater that changes the hazardous stormwater to reusable water after treatment. Hamdan, Troeger, \& Nassar (2011) study stormwater harvesting in Gaza and points that it helps to address water scarcity and reduce urban flooding in the city. DEC NSW (2006) states that sustainable use of water resource should attain high attention to overcome the climate change. One of the sustainable water management system is stormwater harvesting and reuse. It change the nuisance storm water for the use of non-drinking uses. Stormwater harvesting is important to manage flood and water pollution problems in addition to filling the gap of demand for water supply. Vlotman, Wong, \& Schultz (2007) states that reuse of stormwater through design features including the use of water features such as rain gardens, roof gardens, and feature wetlands at different scales is important practice in ecological sustainable development. Several management and simulation models can be used in the process of harvesting stormwater such as Probabilistic Urban Rainwater and Wastewater Reuse Simulator (PURRS), Runoff Quality (RUNQUAL), Storm Tac, and Stormwater Management Model (SWMM) (Elliott \& Trowsdale, 2007).

\subsubsection{Integrated urban water management}

To address the demanding water supply and problem of flooding there is essential to apply a holistic approach other than the conventional traditional approach. This approach, which is efficient, equitable and sustainable management of water resource is called integrated water resource management (IWM). Integrated water management analysis, understand and predict the individual water cycle elements and their interaction. To properly address the problems associated with stormwater such as problems related to waterways and water supply challenges "Integrated water management of stormwater" can play a great role.

Several studies are made to understand, to formulate a new methodology and apply IWM. According to Bahri (2012), the basic aims of integrated urban water management (IUWM) are: secures water and sanitation infrastructure and services; Manage stormwater, wastewater, stormwater drainage, and runoff pollution; Control water borne diseases and epidemics; Reduce water related hazards; and Prevent resource degradation. Vlotman et al. (2007) Study the integration of drainage, water quality and flood management strategies and describe the technological advancements in this process. Vlotman et al. (2007) points that a new paradigm shift is needed in IUWM focusing on integration of potable water, wastewater and stormwater; integration of urban water management from individual building to regional scale, integration of sustainable urban water management into architecture and structure of building, landscape and public art, integration of structural and nonstructural measures in managing urban flood, achieving ecological sustainable development and mitigating flood through managing stormwater.

\subsection{Urban Stormwater drainage management}

Management of urban stormwater includes understanding of urban Stormwater drainage process, historical development, management strategies, design, and hydraulic behavior of the drainage system.

\subsubsection{Urban Stormwater drainage}

Stormwater drainage also called storm drain, storm sewer or drainage well is a process of draining excess water (Harshil H. Gajjar \& M.B.Dholakia, 2014). The use of stormwater sewers, sock ways and storage tanks are common ways used to drain away stormwater, from which stormwater sewers is common method in urban areas (MCGM, 2005). Stormwater drainage system combines both natural and manmade structural features together to serve as stormwater regulator in the form of collector, conveyor, channel, holder, inhibiter, retainer, detainer, infiltrator, diverter, treater or filterer (NDMAGI, 2010). Sundara Kumar et al. (2015) states that mostly storm drainage systems are planned to drain untreated stormwater and in some cases, are designed as a combined sewer to drain sanitary sewage in addition to stormwater.

Rjeily et al. (2017) states that urban flood may result from surcharge of urban drainage system arise from urbanization activities, change in climate and aging and structural failure of urban drainage system utilities. Chen, Leandro, \& Djordjević (2016) also mentions Overloaded sewer as one of the cause for surface flooding in urban areas. The need for modeling of urban drainage is increased to address the urbanization effects such as water quality issues and flooding (Bruen \& Yang, 2006).

\subsubsection{Historical Perspectives of Urban Drainage}

Burian \& Edwards (2004) review several urban drainage system from $300 \mathrm{BC}$ to present chronologically and summarize the outlooks. According to Burian \& Edwards (2004), there were various outlooks about urban drainage systems historically in different time period and location. There was considered as basic natural resources, cleansing mechanism, waste transport medium, concern for flood, wastewater nuisance, and a transmitter of disease. Verworn (2002) study the historical advancement in urban drainage and point out the basic principles of today's urban drainage and future potential advancement. Verworn (2002) states that urban drainage begins at 19th century to drain sewage and stormwater with accepted design standard. Significant advancement is observed in design, hydraulic performance assessment and pollution control and now urban drainage become a part of integrated approach regarding to flood protection and maintaining ecological sustainability.

\subsubsection{Urban stormwater drainage management strategies}

A scientific approach to the management of drainage system is essential to urban areas to mitigate the problems related to it such as flooding and pollution in the fact that densification in urban areas intense the problem Needhidasan \& Nallanathel, (2013). In managing urban drainage system a regime shift from old system to sustainable urban drainage system (SUDS) is mandatory. Torgersen et al. (2014) investigate drivers and preferred methods for improving old system and regime shift from improving the old system to SUDS to minimizing the pluvial flooding that challenges the

\footnotetext{
*corresponding author, Tel: +251910376266

Email address: manaye.teshome@gmail.com
} 
capacity of drainage systems in Scandinavia (large cities from Norway, Denmark and Sweden) and conclude that the regime shift from improving the old system to SUDS significantly improve the capacity of a city to prevent flood.

Nowadays in urban drainage management resilience approaches are become preferable and effective than conventional resistance approach but to adopt the resilience approach well studied indicators should be prepared (Birgani \& Yazdandoost, 2016). Birgani \& Yazdandoost (2016) add resilience concept in urban drainage risk management system to evaluate the effectiveness of urban drainage plans in order to improve the current urban drainage system thus increase their response and recovery capacity under different rainfall events. They develop a set of indicators using a hierarchical fuzzy system and tested in Tehran to evaluate the effectiveness of different drainage plans and conclude that the developed indicators can be used in a decision making criteria.

Abdellatif, Atherton, Alkhaddar, \& Osman (2015) study the effect of climate change to urban drainage system by assessing flood risk using artificial neural network (ANN) downscaling technique to estimate future rainfall. They conclude that the challenge induced by climate change on urban drainage system will increase in the future.

\subsubsection{Design of stormwater drainage system}

A proper design of stormwater system is a vital part of risk management practice. It helps to discharge runoff safely into environment (Needhidasan \& Nallanathel, 2013). Chen et al. (2016) study modeling of sewer discharge and states that overloaded sewer is one of the cause for surface flooding in urban areas (Chen et al., 2016)

The main objective of stormwater drainage system design is control of flood and minimize pollution by determining the physical storage volume of structures. It begins with examining the condition and performance of existing drainage system. A sustainable stormwater drainage system design put through the economic, social and environmental constraints. As Harshil $\mathrm{H}$. Gajjar \& M.B.Dholakia (2014) states, to achieve its goal stormwater drainage system design should support with appropriate information therefore the necessary data should be collected such as: precipitation pattern, rainfall duration, intensity and distribution and soil moisture deficiency at a particular time.

In designing of stormwater drainage system determining the pick discharge and flow behavior is the main task. Al-Rawas \& Valeo (2010) analyze the relation between peak flood discharge and drainage characteristics and signify that drainage area, drainage density, shape factor, slope, watershed mean elevation and urbanizations are the determinant factors of pick discharge of drainage system. Pallard, Castellarin, \& Montanari, (2009) also state that drainage density have higher influence on flood flows. In addition the design consideration shout fit with the location. Archetti, Bolognesi, Casadio, \& Maglionico (2011) study urban drainage in coastal areas and probe that conduit hydraulic conveying capacity and boundary condition of downstream affect the urban drainage network condition and the drainage system of seaside urban areas is not only affected by rainfall but also by sea water level. Several approaches, tools and simulation and decision making models have been used in the designing of stormwater drainage system. Guo \& Zhuge (2008) indicates that the design storm approach is widely used in stormwater management facilities planning and design.

\subsubsection{Hydraulics of Storm Drainage Systems}

In hydraulics of stormwater drainage system, the basic concepts to deal with are flow type assumption and selecting the methods used to determine the pick flow, determining the design frequency, identifying the hydraulic capacity and following the given hydraulic design element principles. Selecting the appropriate method for runoff calculation is a critical issue in the stormwater drainage design. There is no standard method to use for a certain project, the method should select according to the particular project requirement. In the selection of the appropriate method, a designer should consider, at least, the following.1) Information required for design and where to apply this information. 2) Available data for the development of the essential hydraulic information and 3) Watershed conditions that may limit applicability of alternative models.

In stormwater drainage system design hydrologic analysis are used to determine maximum amount of runoff accumulated at storm drainage out late and to estimate runoff quantity. To do so Harshil H. Gajjar \& M.B.Dholakia (2014) mention the following methods: 1) Rational method, 2) Hydrograph method, 3) Empirical method, 4) Rainfall-runoff correlation studies, 5) Prevailing storm direction, 6) Temperature and humidity, and 7) Catchment vegetation cover. While Rene, (2016) lists some of the acceptable methods for estimating peak discharge by Texas department of transportation are: 1) Statistical Analysis of Stream Gauge Data: (Log Pearson III Analyses), 2) Regression Equations Method, 3) Time of Concentration, 4) Rational Method and 5) Hydrograph Method.

Ahn, Cho, Kim, Shin, \& Heo (2014) State that there are several approaches to assess design flood however each method have its own limitation and specific assumption. By studying drawback of several method such as design storm methods and continues simulation method Ahn et al. (2014) developed a new approach called frequency analysis for the simulated annual peak flows (FASAP) of which they conclude it have more advantages. Harshil H. Gajjar \& M.B.Dholakia (2014) study the design of stormwater drainage system for Jodhpur Tekra area of city of Ahmedabad based on 20 years rainfall data using different methods for estimating runoff and conclude that rational method is the best choice than the other methods.

\subsection{Urban Flood Disaster and Risk Management}

\subsubsection{Urban flood disaster}

Urban flooding is a major catastrophic trait, which is a result of manifold and uncertain factors such as, hydrological factors, urbanization, meteorological factors and infrastructure inadequacy and failures that result in property damage, critical infrastructure distraction and loss of lives which can be categorized under manmade and natural factors (Morita, 2014; Mugume \& Butler, 2017; Liu et al., 2016; Atmojo \& Sachro, 2017; Tingsanchali, 2012; Nich, Obi, \& Ubani, 2014; Miller \& Hutchins, 2017). Tingsanchali (2012) remarks urban flood risk 
depends on hazard and vulnerability components of an urban system. While Batica (2015) adds exposure to the flood risk and redefine the urban flood risk as a combination of hazard, exposure and vulnerability.

Knight \& shamseldin, (2006) list causes of flood under natural and manmade as follows. Natural causes includes precipitation, landslides, severe winds, storm surge or unusual high tides, high groundwater levels, glacier melts or collapse, tsunamis and climate change. Whereas Manmade causes are dam failures, embankment failures, floodplain encroachment, and change of land use, inadequate planning controls within whole catchment area, inadequate drainage capacity, inadequate integration and inadequate maintenance. Ogden, Raj Pradhan, Downer, \& Zahner (2011) list imperviousness of surfaces, drainage density, width function, and subsurface storm drainage as a factors that determine urban flooding. Nich et al. (2014) discussed cause of flood, effects of flood and the link between urbanization and flooding in Nigeria. Miller \& Hutchins (2017) assess evidence for the combined effects of urbanization and climate change in United Kingdom and evidences shows that urbanization and climate change increase pluvial and fluvial flooding and reduce water quality in the study area. Petrucci, Pasqua, \& Polemio (2012) study the history of flash flood occurrence in southern Italy drainage basing to find out the real cause for the increment of flood occurrence by comparing rainfall to anthropogenic modifications and conclude that the rainfall in the study area has a decreasing trend but flood damage in increasing this shows that the real cause of flash flood in the area is mismanagement of land use modification. ten Veldhuis et al. (2011) apply probabilistic fault tree analysis to assess and rank causes of urban flood based on their relative contributions. Accordingly, they conclude that component failure and human errors induced more contribution to urban flood probability than sewer overloading. In addition to the physical damage flooding causes water pollution. Nguyen et al., (2017) study the real time urban flood pollution in Can Tho-Vietnam by monitoring water quality parameters in open water such as canals, rivers and lakes, flood water on roads and water in sewers. The result of their study shows that the water quality during flooding is dynamic and have pathogen and contaminants thus is it can cause a health risk as much as sewer water.

Urban Flood induce immediate effects such as inundation and long-term effect like erosion and ponding. It results loss of life and property damages as well highly affects the local economy and overall urban environment (Tingsanchali, 2012). The economic, social and environmental effects of flood are related one another. The effect of flood varies; it depends on location, duration or extent of flood, vulnerability of the area, and values of affected natural and built environment in the affected area.

To avoid urban flooding problems and mitigate flood disaster in urban areas proper flood management strategies should develop. Flood disaster management is controlling of the intensity, volume and speed of runoff water flow. Sewer flooding and combined sewer overflow are the major risk to urban environment which needs to be mitigated with valid and cost effective method such as real time control system
(Garofalo, Giordano, Piro, Spezzano, \& Vinci, 2017). The methods to adopt to mitigate flood can be categorized as structural and non-structural measures (Jha, Bloch, \& Lamond, 2011; Tingsanchali, 2012). For planning and implementing any flood management measure latest, reliable, accurate and timely information is required.

\subsubsection{Integrated Approach to Flood Risk Management}

An integrated approach to flood risk management is essential for sustainable development, to balance the current need and future sustainable development using both structural and nonstructural measures. Price \& Vojinovic (2008) states the need of judicious mix of structural and nonstructural measures to mitigate urban flooding. Tingsanchali (2012) emphasize that implementing structural and non-structural measures is mandatory to achieve successful management of urban flood. Structural measures designed to control floodwater by physical construction or by environmental management and nonstructural measures focused on planning and management of urban environment (Jha, Bloch, \& Lamond, 2011). A specific solution should develop for a particular flooding scenario. The selection of possible solutions will involve identifying technically feasible sets of measures designed to address the particular flooding scenario and should be carried out in consultation with experienced technical specialists. The final strategy should develop through participatory process. Batica (2015) states that integrated flood risk management is a holistic approach to address the flooding problems by participating all stakeholders. It covers all phases in the disaster risk cycle. Tingsanchali (2012) studies integrated urban flood and risk management concepts, plan, policy and operation by raising Thailand as an example and discuss the following points: mostly government alone handle flood disaster management activities specially in developing countries the involvement of NGOs and private sectors is limited, measures are taken individually without proper coordination and measures are mostly reactive focused on responding to the prevailing disaster than proactive measures.

The application of both structural and non-structural measures should follow a particular step accordingly to make flood disaster management effective (Tingsanchali, 2012). The most intensively followed steps in flood disaster management by most of the studies are the following. 1) Flood Forecasting, 2) Reduction of Runoff, 3) Reducing Flood Peaks by Volume Reduction (Constructing Dams and Detention Basins), 4) Reducing Flood Levels, 5) Protection against Inundation (Construction of Embankments) and 5) Flood Plain Zoning (FPZ): According to Tingsanchali (2012) study integrated flood disaster management strategic framework is a cyclic steps comprises of four points these are preparedness, redness, emergency response and recovery and rehabilitation. Batica (2015) states that flood risk management plan focuses on the five pillars which are preparedness, prevention, protection, emergency response and recovery measures which can be categorized under activities before, during and after the flood event (figure 3). Tingsanchali (2012) concludes that for the successful implementation of integrated urban flood disaster management; measures should be planned across administrative and sectoral boundaries, structural and nonstructural measures should implemented integrally,

\footnotetext{
*corresponding author, Tel: +251910376266

Email address: manaye.teshome@gmail.com
} 
implemented measures should be evaluated and monitored properly, community participation should be addressed. Several approaches and computer technologies are incorporated in integrated urban flood management for example Price \& Vojinovic, (2008) develop digital city concept to capture analysis and apply digital information to integral urban stormwater cycle to urban planning to manage urban flood disaster by judicious mix of structural and nonstructural measures.

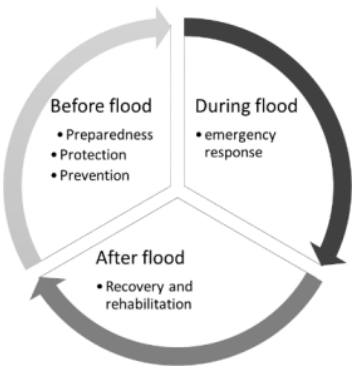

Figure 3. integrated urban flood management cycle (Adopted from: Tingsanchali, 2012; Batica, 2015)

\subsubsection{Integrated Approach to Flood Risk Management: Structural measures}

Structural measures range from heavily-engineered interventions, such as floodways and reservoirs, to more natural approaches like wetlands and greening measures. They cover water management at the catchment and urban level. Heavily engineered structural measures can be highly effective when used appropriately, but they have a characteristics to transfer flood risk from one location to another therefore there acceptance depends on circumstances. In this review several types of measures to prevent urban flooding are observed these includes conveyance, flood storage, drainage systems, infiltration and permeability of urban areas, groundwater management, wetlands and environmental buffers, building design, resilience and resistance, flood defenses, barrier and embankment systems for estuary and coastal flood protection.

Lee et al. (2016) states that structural measures are effective to manage urban flood however they are time consuming and expensive. Chang et al. (2013) propose flood management approaches in Tuku drainage system-Taiwan using drainage flow model combined with 2D overland flow inundation model. Based on their study they propose four structural measures which includes upgrading drainage capacity, using fishpond as retention pond, develop pumping stations and constructing flow diversion culverts. Avila, Avila, \& Sisa (2016) indicates the use of dispersed tanks in SUDS to mitigate flash flood is essential.

Although structural measures play a great role in managing flood they have few drawbacks mentioned in some studies. Alexander, Rashid, Shamsuddin, \& Alam (1998) raised the case of Bangladesh and state that one of the structural measure that is earth embankment enclosure were effectively used to mitigate and control flood however these brought reduction in soil fertility. Levy, Gopalakrishnan, \& Lin (2005) study the challenge and opportunities of flood disaster management strategies and mention some of the drawbacks of structural measures such as structural measures needs large amount of government expenditure, may lead to social and ecological effects, and they may increase damage probability by encouraging development along flood plain areas.

\subsubsection{Integrated Flood Risk Management: Non-Structural Measures}

Nonstructural measures do not require construction of engineered infrastructure but rather need good understanding of flood risk and adequate forecasting systems. Non- structural measures include; flood awareness campaigns, health planning and awareness campaigns, land use planning and flood zoning, flood insurance, risk financing, compensation and tax relief, solid and liquid waste management, emergency planning, rescue, damage avoidance actions and temporary shelter, business and government continuity planning (BGCP), early warning systems, evacuation planning, and flood recovery and reconstruction (Jha et al., 2011; Vlotman et al., 2007; Tingsanchali, 2012). Implementing non-structural measures will maximize the flood mitigation efficiency (Lee et al., 2016). Lee et al. (2016) propose a nonstructural measure to maximize the flood mitigation strategy that is a cooperative operation scheme for urban drainage system that involves sharing of water level information to link centralized and decentralized reservoirs. Levy et al. (2005) study the challenges and opportunities of a non-structural flood disaster management approaches called advances in decision support system (DSS) architecture that plays a vital role in upgrading planning and management of flood. Atmojo \& Sachro (2017) study the establishment of evacuation route from flood affected area to the safe place as a non-structural flood mitigation strategy using GIS.

\subsection{Assessment of flood resilience and flood risk management strategies}

\subsubsection{Adding resilient to flood disaster and risk management}

The current flood management strategies with the use of structural measures become less important to withstand the increasing flood problem in urban areas. Hence a resilience approach to assess and solve the sensitivity of urban environment for flood problem become vital. Resilience approach plays a leading role in assessing sustainability of urban environment to minimize flood risk (Batica, 2015). The resilience approach of urban flood management is efficient and cost effective that provide joint concept of structural and nonstructural measures. It helps to establish flood resilient communities that have effective means to increase adaptation capacity of flooding (Batica, 2015). Resilience measure consider interplay of institution, communication regarding flood risk and development and implementation of flood modeling tools. Flood resilience measures related to activities that improves the capacity building of human resources, better land use management, increased flood preparedness and emergency measures that are taken during and after flood events. Resilient urban environment and urban community have ability to accept, resist, recover and learn from the events. In each flood cycle the capacity of urban system and communities is improved. According to Batica (2015), resilient flood risk management cycle includes the following five elements (5R): Reflect, Relief, Resist, Response, and Recovery.

\footnotetext{
*corresponding author, Tel: +251910376266

Email address: manaye.teshome@gmail.com
} 


\subsubsection{Assessment of flood risk management strategies}

The strategical flood risk assessment consider physical and social components of the urban environment. It covers: The institutional and legal framework; Implementation of strategies; and Social and environmental assessment. Assessment of flood risk management is done by evaluating the integration level of the elements in the risk management cycle undertaken to manage the flood risk. Batica, (2015) develop the concept of maturity level used to assess the flood risk management strategies. It compare each situation with a reference level, which characterizes the complexity and the efficiency of the implemented flood risk management strategy through developing evaluation principles considering flood hazard, exposure and vulnerability. Joyce, Chang, Harji, \& Ruppert (2018) state that food risk assessment requires identification and quantification of flood risk components including hazard, vulnerability, exposure and resilience.

Several methodologies are developed to assess the flood risk management strategies in different areas. Morita (2014) prepare flood risk management method that used to prioritize urban flood risk factors. The method they present is flood damage prediction model based on GIS and XP- SWMM routine that mainly used to calculate flood damage. They apply this model in Kiba drainage area Tokyo- Japan. L. Liu et al., (2016) develop spatial clustering approach (SFCA) to estimate flood risk in stormwater drainage system to improve flood risk assessment. They investigate the developed approach several times and proved that it is effective approach in assessing flood risk in urban areas. Archetti et al. (2011) study the behavior of seaside urban drainage system and develop a method to assess flooding with a function of climate change. They used simplified joint assessment approach and developed flood probability chart for a coastal areas drainage network. Ionuş, Licurici, Pătroescu, \& Boengiu, (2014) study the flood risk in Danube river drainage area Romania and assess flood prone strips flood management strategies and conclude that the effective way to prevent flood in in the flood prone regions is prohibit settlement development in the area. Nich et al., (2014) analyze flood risk management strategies of urban Nigeria. Furlong, De Silva, Gan, Guthrie, \& Considine (2017) study risk management, financial evaluation and funding of seven waste water and stormwater reuse projects in Australia and conclude that responsible parties are equipped to identify potential risks but some upgrading are needed in funding.

\subsubsection{Flood resilience assessment}

Assessment of flood resilience of urban area helps to identify hot spots and to draw efficient recommendation of effective flood management strategies. In this process identifying the scale and the physical components of urban system i.e. function and services is vital (Batica, 2015). Batica (2015) states that flood resilience evaluation expressed through the value of flood resilience index (FRI) that uses a set of indicators for quantification. In the process of quantification of urban flood resilience the functional analysis is used to describe the structure of the urban system and the relation between different components. Lee et al. (2016) also develop a resilience index that helps to assess the ability of the system to mitigate, restore and recover from flood risk.
Resilience of urban drainage system should consider the interaction between treats, performance of the system and risk of failure however the current resilience approach is depend only failure due to specific design storm (Mugume \& Butler, 2017). Mugume \& Butler (2017) evaluate urban drainage system performance using a global resilience analysis (GRA) considering the system subjection to wider failure scenario and the method is applied on existing urban drainage system of city of Kampala-Uganda and proved to be successful. Shiau et al. (2012) study flood vulnerability of Taiwan where huge land development is undergoing by developing psychographic drainage- inundation model and define flood vulnerability index as the product of exposure score and hazard score. Joyce, Chang, Harji, \& Ruppert (2018) develop a concept of coupling flood risk assessment and drainage infrastructure resilience to evaluate flood hazard and its cause they thought which is less complex to classify hazards. Coupling of flood risk and resilience needs to carefully understand and based on predicted hazard, vulnerability and adaptive capacity.

\subsection{Flood modeling}

Flood disaster management depends on the scientific knowledge, evidence based techniques and the application of science and technology. Flood disaster management develops and implemented through analysis and information gathering. Data gathered, organized and displayed to determine the size and scope of flood disaster management. In flood disaster management multi-temporal spatial data is required and the use of tools such as satellite remote sensing is required to get information over a large area. Several tools and models are used to arrange and display information for the use of technical experts, to explain programmers of flood damage reduction to the decision-makers, and to communicate real time forecasts and warnings to the public (Gilles \& Moore, 2010; UNISDR, 2002).

Several studies are made regarding to the use of supportive technologies for modeling and decision making. Decision making in flood management now a days is supported by remote sensing technologies which makes mapping of flood inundation area easy. Images taken during flooding by ERS-1 SAR can clearly show the inundated area (Badji \& Dautrebande, 1997). J. Liu, Chen, Zhang, \& Flury (2010) study to improve flood forecasting by coupling Xinanjang model to kinematic flow model. Rjeily et al. (2017) develop a flood forecasting system by measuring depth variation in manhole using Nonlinear Auto Regressive exogenous (NARX) neural network. Wei et al. (2014) propose two staged intelligence based pumping control (TWOPC) model to solve the complexity of estimating the required pump flow and finding the favorable combination of pumps to install for mitigating urban flood.

Numerical methods with brad assumption and governing equation used to describe the flooding natural and physical phenomena. The base of unsteady flow routing computer simulation are the Navier- Stokes equation derive using differential equation of motion and continuity given in Equation 1.

$$
d p / d t+d u / d x+d v / d y+d w / d z=0
$$

\footnotetext{
*corresponding author, Tel: +251910376266

Email address: manaye.teshome@gmail.com
} 
Where $\rho$ is fluid density, $\mathrm{x}, \mathrm{y}$, and $\mathrm{z}$ are Cartesian coordinates, $\mathrm{t}$ is time, $\mathrm{u}, \mathrm{v}$, and $\mathrm{w}$ are velocity components in the $\mathrm{x}, \mathrm{y}$, and $\mathrm{z}$ directions, respectively. These equation are applicable in any situation but computational limitations determine the degree of simulation. Depending on the above equation one dimensional, two dimensional and three dimensional models can be prepared but 1D and 2D are more applicable in this days whereas 3D is unjustifiable. 1D models are unable to simulate complex flood events and 2D models are failed to simulate structural elements thus the application of coupling of 1D and 2D models become essential. Depending on the complexity of flooding event from simple to advanced hydraulic modeling can be used (Gilles \& Moore, 2010). Pallard et al. (2009) analyze the relation between drainage density and flood statistics by carry out a numerical simulation, hydrologic model and real world data investigation. Bruen \& Yang (2006) state that the need for modeling of urban drainage is increased to address the urbanization effects such as water quality issues and flooding.

Technological advancement and models provide a ground to extract important data. Modeling used for data collection, model development, numerical simulation, post processing and theoretical assumption (Gilles \& Moore, 2010). Drainage network can be extracted from DEM but selecting the appropriate method is vital. Rueda, Noguera, \& Martínez-Cruz (2013) present a new methodology used to extract drainage network from DEM based on D8- approaches that simulate surface overflow with more elaborative way. Rueda et al. (2013)probed that the developed method is simple, elegant and efficient. Al-Rawas \& Valeo (2010) study the relation between characteristics of wadi drainage and peak flood flows in the study area of northern Oman. In this study digital elevation model (DEM) was used to extract the watershed characteristics and to assess the effect multiple regression was used. State that inundation map are the most useful results produced from simulation.

Several models have been used in assessing flood risk. Chang et al. (2013) study the increased flood damage in Tuku lowland -Taiwan due to climate change and evaluate the flood management strategies with damage losses estimation using integrated drainage inundation model by combing a drainage flow models with 2D overland flow inundation model. Villarini et al. (2009) develop flood frequency analysis framework based on a tool for modeling time series under nonstationary conditions called Generalized Additive Models for Location, Scale and Shape parameters (GAMLSS). These method is applied to annual maximum peak discharge records for Little Sugar Creek, a highly urbanized watershed which drains the urban core of Charlotte, North Carolina and proved to be the best method that can provide statistical modeling framework. Morita (2014) uses GIS and XP-SWMM to propose flood risk assessment framework in Tokyo-Japan. Jahanbazi \& Egger, (2014) apply and compare two different dual drainage models which are static model and HYSTEM EXTRAN 2D model to assess urban flood in Hamburg, Germany and conclude that, HYSTEM EXTRAN 2D model is more advantageous than static model. Nanía, Leon, \& García (2014) use 1D model with four specific modules to simulate dual drainage and urban flood. The four modules are simulation of transformation of rainfall-runoff, street network 1D routing, street inlet flow interception, surface water and ground water interaction using EPA-SWMM5. The proposed module is applied in metropolitan area of Chicago and proved to be essential tool in stormwater management and urban flood risk assessment.

Coupling of 1D and 2D modeling become a widely used approach in urban drainage modeling. Bertsch, Glenis, \& Kilsby, (2017) use CityCAT 1D/2D urban flood modeling to develop a GIS routine that allows synthetic storm drain inlet network generation. Pathirana et al. (2011) study to integrate 1D and 2D models to use in urban drainage planning and develop a new 2D inundation model and coupled with 1DSWMM model to simulate inundation in urban areas due to surcharge. They conclude that coupled $1 \mathrm{D} / 2 \mathrm{D}$ model is stable, capable to deal diverse flow conditions and able to simulate wetting and drying process. Chen et al. (2016) Propose a new simulation approach to understand the dynamic relation between manhole and ground surface using coupled 1D/2D SIPSON/P-DWave surface and sewer flow modeling. Kim, Sanders, Han, Kim, \& Famiglietti (2014) study coupling of 1D drainage model (SWMM) with 2D inundation model can be used to prepare flood extent map due to predicted surcharge and Kim et al., (2014) points that SWMM is very sensitive to prediction of surcharge thus appropriate care should be taken. Fang \& Su (2006) Establish integrated 1D and 2D hydraulic model for simulating the process of urban stormwater flooding where this model simulates 1D flow underground water pipes and drainage channels and 2D overland flow. Fang \& Su (2006) conclude that this model gives a detailed spatial flood risk information such as water depth, duration of inundation and flow velocity during flooding.

Several studies used models to estimate rainfall-runoff, forecast flood and warning. Abdellatif, Atherton, Alkhaddar, \& Osman (2015) implements artificial neural network (ANN) downscaling technique to estimate future rainfall in their study of the effect of climate change in urban drainage system. The conceptual rainfall-runoff model called Xinanjang model which simulate runoff and overland flow routing based on topographic and land use data is a preferable model in china used to forecast flooding (J. Liu et al., 2010). Ahn et al. (2014) study several methods used to assess design flood and find out limitations in each methodologies thus propose a new method called flood frequency analysis for the simulated annual peak flow (FASAP) and verified it by comparing with conventional approaches. Bruen \& Yang (2006) propose an effective method used to forecast flooding in urban drainage system by upgrading the conventional hydraulic model that was developed by HYDROWORKS through combining Black Box model to it. J. Liu, Chen, Zhang, \& Flury (2010) study to improve flood forecasting by coupling Xinanjang model to kinematic flow model. Chang, Lin, \& Lai (2018) develops a flood warning system in Jhonghe, New Taipei city, Taiwan which has been frequently affected by urban drainage floods using a wireless sensor which detect water level. In this study SWMM is used to estimate the average rate of water level increase.

Time of concentration for drainage are can be derived from several models. Y. Zhou, Guo, \& Baetz (2016) propose a method to estimate the time of concentration for drainage areas

\footnotetext{
*corresponding author, Tel: +251910376266
}

Email address: manaye.teshome@gmail.com 
which comprises of parallel sub areas. The proposed method is to use a runoff weighted average of time travel through the parallel sub areas. Y. Zhou, Guo, \& Baetz (2016) probed that the proposed method is more accurate and appropriate than the convention method. Y. Zhou, Guo, \& Baetz (2016) uses continues simulation and design storm modeling to propose a new method to estimate the time concentration in drainage areas composed of parallel sub areas.

In water system moeling usually some sort of uncertainity may present. This uncertainities should be assessed and handled to do this different uncertainity analysis are applied (Fu, Butler, Khu, \& Sun, 2011). Fu et al. (2011) present a randomness theroy to asessess two uncertainitties that are impercise probabilities from rainfall data and fuzziness from model parametrs in sewer flood estimation framawork. In stormwater management facilities planning and design the design strom approach is widely used but according to Guo \& Zhuge (2008), there are problems asscociated with these approach and Guo \& Zhuge (2008) develop another approach called analyytical probablisitc flood routing to fill tha aps of design strom modeling aproach.

Selecting the approprite model is essential. The degree of data needed and software limitation will determine the selection of suitable modeling package (Gilles \& Moore, 2010). Elliott \& Trowsdale (2007) compare ten available stormwater models in relation to elements relevant to modeling sustainable drainage system. The models compared are model for urban sewer (MOUSE), model for urban stormwater improvement conceptualizations (MUSIC), program for predicting pollution particles passage through pits, puddles and ponds - urban catchment model (P8-UCM), probabilistic urban rainwater and wastewater reuse simulator (PURRS), runoff quality (RUNQUAL), source loading and management model (SLAMM), Storm Tac, stormwater management model (SWMM), urban volume and quality (UVQ), and water balance management (WBM). Elliott \& Trowsdale (2007) states that MOUSE and SWMM are applicable I wide range of uses but they are complex and not easy to be used by the general public rather needs professionals; Storm Tac and PURRS have limited uses; and the other six models have moderate uses.

\section{DISCUSSION}

This review of recent studies on urban stormwater drainage system for urban flood management shows the broadness of the urban flood management which need the integrated work on the aspects of managing stormwater, drainages systems, and flood disaster and risk with stakeholder participation and use of technological advancement. It is a vast concept which determine the social, economic and environmental aspects. Several studies have been conducted to address the problems of urban flooding but urban flooding is still increasing. Therefore by assessing past, present and future situation of flooding well integrated urban flood management strategies can be developed. This selection covers some of the possible study directions.

\subsection{Urban Stormwater Management}

Stormwater is the basic natural component challenging urban areas with urbanization effects. Due its complexity, managing stormwater demand the use of well defied methods, tools, techniques and simulation models. Since the problem is persistent and increasing future research should explore more integrated approach to change the nuisance stormwater to a useful resource. The comprehensive study on the approach, tools and computer models used for stormwater management should studied to develop more useful approach. Future studies should focus in incorporating stormwater in integrated urban water management strategies. In addition the social, economic, and ecological impacts of BMPs and there integration to nonstructural measures should studied.

\subsection{Urban Stormwater drainage management}

The challenge induced by climate change and urbanization on urban drainage system will increase in the future (Needhidasan \& Nallanathel, 2013). To handle this increasing challenge future studies should continue exploring the more effective way to apply sustainable urban drainage system and to realize the proper regime shift from conventional system to SUDS. Integrating natural features and manmade structural features in deigning of urban drainage system should encouraged.

Little attention has been given for the collaboration of different stakeholders in urban stormwater drainage management process; the importance of community participation has been highlighted but only discussed in general terms. Future studies should probe the approaches to strengthen community participation. In hydrological application several approaches have been used to assess the design flood but each method has its own limitations and specific assumptions thus selecting the appropriate approach is critical but not easy (Ahn et al., 2014). It is therefore recommended that well organized, comprehensive and detailed studies on hydrological approaches should conducted. Incorporating resilience approach in urban stormwater drainage management is a new concept gaining attention and believed to be a good approach in identifying the risk associated with drainage systems but developing and applying indicators is challenging. Thus future research should be conducted focusing on developing resilience indicators for urban stormwater drainage system that consider social, economic and environmental aspects.

\subsection{Urban Flood Disaster and Risk Management}

The importance of assessing urban flood factors as a flood management strategy has been recognized by many researchers. Detail studies on the flooding strengthen the preflood management strategies and enhance mitigation measures thus minimize the damage. It is therefore suggested that futures studies should conduct a more detailed study on identification of the flood causative factors to the specific location. In most of the studies immediate effects of urban flooding are studied, the long term social, economic and environmental effects are less considered. Research giving attention on the long term effects of urban flooding should be conducted to understand its overall effect on urban environment.

\footnotetext{
*corresponding author, Tel: +251910376266

Email address: manaye.teshome@gmail.com
} 
Many studies have been conducted on SUDS and several techniques, tools and modeling approaches are evolved over time but still their application is challenging and unable to mimic the natural response of the system (Q. Zhou, 2014). Therefore detailed studies on SUDS should continue, specifically studies focused on operation and maintenance of SUDS, interaction with other water bodies, and institutional framework should be conducted.

Integrated urban flood management is a holistic approach to deal with urban flooding (Batica, 2015), that gain many researcher's attention. However detail studies should be conducted to achieve a judicious mix of integrated structural and nonstructural strategies, and to understand the mechanism behind to participatory process for active engagement of stakeholders. In addition future studies should assess the economic and ecological impacts of structural measures on urban environment.

\subsection{Assessment of flood resilience and flood risk management strategies}

The resilience approach in urban flood management is a new leading approach that based on set of indicators and it has attract most attention (Batica, 2015). However, the development of indicators is very challenging and needs integrated studies. Regarding to this, since the flooding scenario depends on the location characteristics, more cases should be studied to develop resilience indicators according to the local characteristics.

In terms of flood risk assessment, future studies focusing on investigation of different approaches, development of completer set of indicators, participation of different stakeholders and use of appropriate modeling techniques need to be conducted.

\subsection{Flood modeling}

Hydraulic-hydrologic flood models have been used intensively in every aspects of urban flood management. Lots of modeling techniques which can be one dimensional, two dimensional or coupling the two with many software tools are emerged. However each models have its own limitation and uncertainties. To minimize these, detailed investigation on the available modeling approaches should be conducted.

\section{CONCLUSION}

This study reviews popular issues in relation to urban stormwater and urban flood management. The selected 78 papers were discussed from the aspects of urban stormwater management, urban drainage management, urban flood disaster management, assessment of flood resilience and flood risk management strategies and flood models. Although a growing body of research covers the areas mentioned above, the complexity of urban flood and its increasing risk yet need further studies. In the discussion part of this paper the future research trends are identified which can be a road map for researchers in the field of urban flood management. The integration of different urban flood management strategies, community participation, the net environmental impacts of applied flood management structures, urban flood resilience and hydraulic-hydrologic flood modeling techniques are the important topics need further investigations.

\section{REFERENCES}

Abdellatif, M., Atherton, W., Alkhaddar, R., \& Osman, Y. (2015). Flood risk assessment for urban water system in a changing climate using artificial neural network. Natural Hazards, 79(2), 1059-1077. https://doi.org/10.1007/s11069-015-1892-6

Ahn, J., Cho, W., Kim, T., Shin, H., \& Heo, J. H. (2014). Flood frequency analysis for the annual peak flows simulated by an event-based rainfall-runoff model in an urban drainage basin. Water (Switzerland), 6(12), 3841-3863. https://doi.org/10.3390/w6123841

Al-Rawas, G. A., \& Valeo, C. (2010). Relationship between wadi drainage characteristics and peak-flood flows in arid northern oman. Hydrological Sciences Journal, 55(3), 377-393. https://doi.org/10.1080/02626661003718318

Alexander, M. J., Rashid, M. S., Shamsuddin, S. D., \& Alam, M. S. (1998). Flood control, drainage and irrigation projects in Bangladesh and their impact on soils: an empirical study. Land Degradation and Development, 9(3), 233-246. https://doi.org/10.1002/(SICI)1099145X(199805/06)9:3<233::AID-LDR277>3.0.CO;2-W

Archetti, R., Bolognesi, A., Casadio, A., \& Maglionico, M. (2011). Development of flood probability charts for urban drainage network in coastal areas through a simplified joint assessment approach. Hydrology and Earth System Sciences, 15(10), 3115-3122. https://doi.org/10.5194/hess-15-3115-2011

Asfaw, B. (2016). Assessment of Stormwater Drainage Systems Asfaw, B. (2016). Assessment of Stormwater Drainage Systems in Kemise Town.in Kemise Town.

Atmojo, P. S., \& Sachro, S. S. (2017). Disaster Management: Selections of Evacuation Routes Due to Flood Disaster. In Procedia Engineering (Vol. 171, pp. 1478-1485). https://doi.org/10.1016/j.proeng.2017.01.475

Avila, H., Avila, L., \& Sisa, A. (2016). Dispersed Storage as Stormwater Runoff Control in Consolidated Urban Watersheds with Flash Flood Risk. Journal of Water Resources Planning and Management, 142(12), 04016056. https://doi.org/10.1061/(ASCE)WR.1943-5452.0000702

Badji, M., \& Dautrebande, S. (1997). Characterization of flood inundated areas and delineation of poor drainage soil using ERS-1 SAR imagery. Hydrological Processes, 11(10), 1441-1450. https://doi.org/10.1002/(SICI)1099-1085(199708)11:10<1441::AIDHYP527>3.0.CO;2-Y

Bahri, A. (2012). Integrated Urban Water Management. TEC Background Papers. https://doi.org/10.1080/09614520701469427

Batica, J. (2015). Methodology for Flood Resilience Assessment in Urban Environments and Mitigation Strategy Development, (September), 229.

Bertsch, R., Glenis, V., \& Kilsby, C. (2017). Urban flood simulation using synthetic storm drain networks. Water (Switzerland), 9(12). https://doi.org/10.3390/w9120925

Birgani, Y. T., \& Yazdandoost, F. (2016). Resilience in urban drainage risk management systems. Proceedings of the Institution of Civil Engineers - Water Management, 169(1), 3-16. https://doi.org/10.1680/wama.14.00043

Bruen, M., \& Yang, J. (2006). Combined Hydraulic and Black-Box Models for Flood Forecasting in Urban Drainage Systems. Journal of Hydrologic Engineering, 11(6), 589-596. https://doi.org/10.1061/(ASCE)1084-0699(2006)11:6(589)

Burian, S. J., \& Edwards, F. G. (2004). Historical Perspectives of Urban Drainage Steven. Global Solutions for Urban Drainage, (479), 1-16.

Chang, H.-K., Lin, Y.-J., \& Lai, J.-S. (2018). Methodology to set trigger levels in an urban drainage flood warning system - an application to Jhonghe, Taiwan. Hydrological Sciences Journal, 63(1), 31-49. https://doi.org/10.1080/02626667.2017.1409897

Chang, H.-K., Tan, Y.-C., Lai, J.-S., Pan, T.-Y., Liu, T.-M., \& Tung, C.-P. (2013). Improvement of a drainage system for flood management with assessment of the potential effects of climate change. Hydrological Sciences Journal, 58(8), 1581-1597. https://doi.org/10.1080/02626667.2013.836276

Chen, A. S., Leandro, J., \& Djordjević, S. (2016). Modelling sewer discharge 
via displacement of manhole covers during flood events using 1D/2D SIPSON/P-DWave dual drainage simulations. Urban Water Journal, 13(8), 830-840. https://doi.org/10.1080/1573062X.2015.1041991

Elliott, A. H., \& Trowsdale, S. A. (2007). A review of models for low impact urban stormwater drainage. Environmental Modelling and Software, 22(3), 394-405. https://doi.org/10.1016/j.envsoft.2005.12.005

Ellis, J. B., \& Viavattene, C. (2014). Sustainable urban drainage system modeling for managing urban surface water flood risk. Clean - Soil, Air, Water, 42(2), 153-159. https://doi.org/10.1002/clen.201300225

Evers, M. (2012). Participation in Flood Risk Management An introduction and recommendations for implementation, (1), 1-21.

Fang, X., \& Su, D. (2006). An integrated one dimensional and two dimensional urban stormwater flood simulation model. JAWRA Journal of the American Water ..., 77042, 713-724. Retrieved from http://onlinelibrary.wiley.com/doi/10.1111/j.17521688.2006.tb04487.x/abstract

Fu, G., Butler, D., Khu, S. T., \& Sun, S. (2011). Imprecise probabilistic evaluation of sewer flooding in urban drainage systems using random set theory. Water Resources Research, 47(2), 1-13. https://doi.org/10.1029/2009WR008944

Furlong, C., De Silva, S., Gan, K., Guthrie, L., \& Considine, R. (2017). Risk management, financial evaluation and funding for wastewater and stormwater reuse projects. Journal of Environmental Management, 191, 83-95. https://doi.org/10.1016/j.jenvman.2017.01.007

Garofalo, G., Giordano, A., Piro, P., Spezzano, G., \& Vinci, A. (2017). A distributed real-time approach for mitigating $\mathrm{CSO}$ and flooding in urban drainage systems. Journal of Network and Computer Applications, 78(November 2016), 30-42. https://doi.org/10.1016/j.jnca.2016.11.004

Gilles, D., \& Moore, M. (2010). Review of Hydraulic Flood Modeling Software used in Belgium , The Netherlands, and The United Kingdom. International Perspectives in Water Resource Management, 15. Retrieved from http://www.iihr.uiowa.edu/education 1/international/UK/projects_files/i pwrsm_paper_gilles_moore_Dan_editted.pdf

Guo, Y., \& Zhuge, Z. (2008). Analytical probabilistic flood routing for urban stormwater management purposes. Canadian Journal of Civil Engineering, 35(5), 487-499. https://doi.org/10.1139/L07-131

Haghighatafshar, S., Nordlöf, B., Roldin, M., Gustafsson, L. G., la Cour Jansen, J., \& Jönsson, K. (2018). Efficiency of blue-green stormwater retrofits for flood mitigation - Conclusions drawn from a case study in Malmö, Sweden. Journal of Environmental Management, 207, 60-69. https://doi.org/10.1016/j.jenvman.2017.11.018

Hamdan, S. M., Troeger, U., \& Nassar, A. R. (2011). Quality Risks of Stormwater Harvesting in Gaza. Journal of Environmental Science and Technology, 55-64. https://doi.org/10.3923

Harshil H. Gajjar, \& M.B.Dholakia, D. (2014). Storm Water Network Design of Jodhpur Tekra Area of City of Ahmedabad. International Journal of Engineering Development and Research, 2(1), 744-747.

Ionuş, O., Licurici, M., Pătroescu, M., \& Boengiu, S. (2014). Assessment of flood-prone stripes within the Danube drainage area in the South-West Oltenia Development Region, Romania. Natural Hazards, 75(1), 6988. https://doi.org/10.1007/s11069-013-0720-0

Jahanbazi, M., \& Egger, U. (2014). Application and comparison of two different dual drainage models to assess urban flooding. Urban Water Journal, 11(7), 584-595. https://doi.org/10.1080/1573062X.2013.871041

Jha, A. K., Bloch, R., \& Lamond, J. (2011). Cities and Flooding: A Guide to Integrated Urban Flood Risk Management for the 21st Century. https://doi.org/10.1596/978-0-8213-8866-2

Jiang, Y., Zevenbergen, C., \& Fu, D. (2017). Understanding the challenges for the governance of China's "sponge cities" initiative to sustainably manage urban stormwater and flooding. Natural Hazards, 89(1), 521529. https://doi.org/10.1007/s11069-017-2977-1

Joyce, J., Chang, N. Bin, Harji, R., \& Ruppert, T. (2018). Coupling infrastructure resilience and flood risk assessment via copulas analyses for a coastal green-grey-blue drainage system under extreme weather events. Environmental Modelling and Software, 100, 82-103. https://doi.org/10.1016/j.envsoft.2017.11.008

Kim, B., Sanders, B. F., Han, K., Kim, Y., \& Famiglietti, J. S. (2014). Calibration of stormwater management model using flood extent data. Proceedings of the Institution of Civil Engineers - Water Management,
167(1), 17-29. https://doi.org/10.1680/wama.12.00051

Knight, D. W., \& Shamseldin, A. Y. (2006). River basin modelling for flood risk mitigation. UK, london: Taylor \& Francis. Retrieved from https://books.google.co.in/books/about/River_Basin_Modelling_for_Fl ood_Risk_Mit.html?id=OlCMpETIJOMC\&redir_esc $=y$

Lamond, J. E., Rose, C. B., \& Booth, C. A. (2015). Evidence for improved urban flood resilience by sustainable drainage retrofit. Proceedings of the Institution of Civil Engineers - Urban Design and Planning, 168(2), 101-111. https://doi.org/10.1680/udap.13.00022

Lee, E. H., Lee, Y. S., Joo, J. G., Jung, D., \& Kim, J. H. (2016). Flood reduction in urban drainage systems: Cooperative operation of centralized and decentralized reservoirs. Water (Switzerland), 8(10). https://doi.org/10.3390/w8100469

Levy, J. K., Gopalakrishnan, C., \& Lin, Z. (2005). Advances in decision support systems for flood disaster management: Challenges and opportunities. International Journal of Water Resources Development, 21(4), 593-612. https://doi.org/10.1080/07900620500258117

Liu, J., Xi Chen, X., Zhang, J., \& Flury, M. (2010). Coupling the Xinanjiang model to a kinematic flow model based on digital drainage networks for flood forecasting Jintao. HYDROLOGICAL PROCESSES, 2274(November 2008), 2267-2274. https://doi.org/10.1002/hyp

Liu, L., Li, X., Xia, G., Jin, J., \& Chen, G. (2016). Spatial fuzzy clustering approach to characterize flood risk in urban storm water drainage systems. Natural Hazards, 83(3), 1469-1483. https://doi.org/10.1007/s11069-016-2371-4

MCGM. (2005). Storm Water Drainage. Mumbai City Development Plan 2005-2025, 98-102. Retrieved from http://www.mcgm.gov.in/irj/go/km/docs/documents/

Miller, J. D., \& Hutchins, M. (2017). The impacts of urbanisation and climate change on urban flooding and urban water quality: A review of the evidence concerning the United Kingdom. Journal of Hydrology: Regional Studies, 12(January), 345-362. https://doi.org/10.1016/j.ejrh.2017.06.006

Morita, M. (2014). Flood risk impact factor for comparatively evaluating the main causes that contribute to flood risk in urban drainage areas. Water (Switzerland), 6(2), 253-270. https://doi.org/10.3390/w6020253

Morsy, M. M., Goodall, J. L., Shatnawi, F. M., \& Meadows, M. E. (2016). Distributed Stormwater Controls for Flood Mitigation within Urbanized Watersheds Case Study of Roacky Branch Watershed in Colomia, South Carolina. Journal of Hydrologic Engineering. https://doi.org/0.1061/ (ASCE)HE.1 943-558 4 .00014 30

Mugume, S. N., \& Butler, D. (2017). Evaluation of functional resilience in urban drainage and flood management systems using a global analysis approach. Urban Water Journal, 14(7), 727-736. https://doi.org/10.1080/1573062X.2016.1253754

Nanía, L. S., Leon, A. S., \& García, M. H. (2014). Hydrologic-Hydraulic Model for Simulating Dual Drainage and Flooding in Urban Areas : Application to a Catchment in the Metropolitan Area of Chicago. Journal of Hydrologic Engineering, 20(2005), 1-13. https://doi.org/10.1061/(ASCE)HE.1943-5584.0001080,04014071

Nation, U. (2002). Key Elements of Flood Disaster Management, 23-46. Retrieved from www.un.org/esa/sustdev/.../flood_guidelines_sec02.pdf

NDMAGI, N. D. M. A. G. O. I. (2010). National Disaster Management Guidelines: Management of Urban Flooding. New Delhi.

Needhidasan, S., \& Nallanathel, M. (2013). Design of storm water drains by rational method-an approach to storm water management for environmental protection. International Journal of Engineering and Technology, 5(4), 3203-3214.

Negi Mohita. (n.d.). Flood Disaster Management: 6 Major Steps of Flood Disaster Management. Retrieved March 26, 2018, from http://www.yourarticlelibrary.com/disasters/flood-disastermanagement-6-major-steps-of-flood-disaster-management/14062/

Nguyen, H. Q., Radhakrishnan, M., Huynh, T. T. N., Baino-Salingay, M. L., Ho, L. P., Steen, P. Van der, \& Pathirana, A. (2017). Water Quality Dynamics of Urban Water Bodies during Flooding in Can Tho City, Vietnam. Water, 9(4), 260. https://doi.org/10.3390/w9040260

Nich, A., Obi, I., \& Ubani, O. (2014). Analysis of Flood Risk Management in Nigerian Urban Environment. Journal of Environment and Earth Science, 4(6), 110-115.

Ogden, F. L., Raj Pradhan, N., Downer, C. W., \& Zahner, J. A. (2011). Relative importance of impervious area, drainage density, width

*corresponding author, Tel: +251910376266

Email address: manaye.teshome@gmail.com 
function, and subsurface storm drainage on flood runoff from an urbanized catchment. Water Resources Research, 47(12), 1-12. https://doi.org/10.1029/2011WR010550

Pallard, B., Castellarin, A., \& Montanari, A. (2009). A look at the links between drainage density and flood statistics. Hydrology and Earth System Sciences, 13(7), 1019-1029. https://doi.org/10.5194/hess-131019-2009

Pathirana, A., Tsegaye, S., Gersonius, B., \& Vairavamoorthy, K. (2011). A simple 2-D inundation model for incorporating flood damage in urban drainage planning. Hydrology and Earth System Sciences, 15(8), 2747-2761. https://doi.org/10.5194/hess-15-2747-2011

Pedrozo-Acuña, A., Moreno, G., Mejía-Estrada, P., Paredes-Victoria, P., Breña-Naranjo, J. A., \& Meza, C. (2017). Integrated approach to determine highway flooding and critical points of drainage. Transportation Research Part D: Transport and Environment, 50, 182-191. https://doi.org/10.1016/j.trd.2016.11.004

Petit-Boix, A., Sevigné-Itoiz, E., Rojas-Gutierrez, L. A., Barbassa, A. P., Josa, A., Rieradevall, J., \& Gabarrell, X. (2015). Environmental and economic assessment of a pilot stormwater infiltration system for flood prevention in Brazil. Ecological Engineering, 84, 194-201. https://doi.org/10.1016/j.ecoleng.2015.09.010

Petit-Boix, A., Sevigné-Itoiz, E., Rojas-Gutierrez, L. A., Barbassa, A. P., Josa, A., Rieradevall, J., \& Gabarrell, X. (2017). Floods and consequential life cycle assessment: Integrating flood damage into the environmental assessment of stormwater Best Management Practices. Journal of Cleaner Production, 162, 601-608. https://doi.org/10.1016/j.jclepro.2017.06.047

Petrucci, O., Pasqua, A. A., \& Polemio, M. (2012). Flash flood occurrences since the 17th century in steep drainage basins in southern Italy. Environmental Management, 50(5), 807-818. https://doi.org/10.1007/s00267-012-9935-1

Price, R. K., \& Vojinovic, Z. (2008). Urban food disaster management. Urban Water Journal, 5(3), 259-276. https://doi.org/10.1080/15730620802099721

Rene, G. (2016). Hydraulic Design Manual.

Rjeily, Y. A., Abbas, O., Sadek, M., Shahrour, I., \& Chehade, F. H. (2017). Flood forecasting within urban drainage systems using NARX neural network. Water Science and Technology, 76(9), 2401-2412. https://doi.org/10.2166/wst.2017.409

Rossman, L. A. (2015). Storm Water Management Model User's Manual, (EPA/600/R-14/413b), 1-353. Retrieved from http://www.epa.gov/water-research/storm-water-management-modelswmm

Rueda, A., Noguera, J. M., \& Martínez-Cruz, C. (2013). A flooding algorithm for extracting drainage networks from unprocessed digital elevation models. Computers and Geosciences, 59, 116-123. https://doi.org/10.1016/j.cageo.2013.06.001

Schueler, T. R. (1994). The Importance of Imperviousness. Watershed Protection Techniques, 1(3), 100-111.

Sharma, D. (2008). Sustainable Drainage System (SuDs) for Stormwater Management: A Technological and Policy Intervention to Combat Diffuse Pollution. 11th International Conference on Urban Drainage, Edinburgh, Scotland, UK, 2008, 1-10.

Shiau, J. T., Chen, C. N., \& Tsai, C. T. (2012). Physiographic Drainage-
Inundation Model Based Flooding Vulnerability Assessment. Water Resources Management, 26(5), 1307-1323. https://doi.org/10.1007/s11269-011-9960-5

Sundara Kumar, P., Santhi, T., Manoj Srivatsav, P., Sreekanth Reddy, S. V., Anjaneya Prasad, M., \& Praveen, T. V. (2015). Storm water drainage design (Case study Vijayawada). International Journal of Earth Sciences and Engineering, 8(2), 507-511.

Tahmasebi Birgani, Y., \& Yazdandoost, F. (2014). A framework for evaluating the persistence of urban drainage risk management systems. Journal of Hydro-Environment Research, 8(4), 330-342. https://doi.org/10.1016/j.jher.2014.04.004

ten Veldhuis, J. A. E., Clemens, F. H. L. R., \& van Gelder, P. H. A. J. M. (2011). Quantitative fault tree analysis for urban water infrastructure flooding. Structure and Infrastructure Engineering, 7(11), 809-821. https://doi.org/10.1080/15732470902985876

Tingsanchali, T. (2012). Urban flood disaster management. In Procedia Engineering (Vol. 32, pp. 25-37). https://doi.org/10.1016/j.proeng.2012.01.1233

Torgersen, G., Bjerkholt, J. T., \& Lindholm, O. G. (2014). Addressing flooding and SuDS when improving drainage and sewerage systems-A comparative study of selected Scandinavian cities. Water (Switzerland), 6(4), 839-857. https://doi.org/10.3390/w6040839

Underwood, S. J. (2006). Cloud-to-Ground Lightning Flash Parameters Associated with Heavy Rainfall Alarms in the Denver, Colorado, Urban Drainage and Flood Control District ALERT Network. Monthly Weather Review, 134(9), 2566-2580. https://doi.org/10.1175/mwr3201.1

UNISDR. (2002). Guidelines for Reducing Flood Losses. United Nations Headquarters (UN), Available on-Line at: Https://Www.Unisdr.Org/We/Inform/Publications/558, 79.

Verworn, H.-R. (2002). Advances in urban-drainage management and flood protection. Philosophical Transactions of the Royal Society A: Mathematical, Physical and Engineering Sciences, 360(1796), 14511460. https://doi.org/10.1098/rsta.2002.1009

Villarini, G., Smith, J. A., Serinaldi, F., Bales, J., Bates, P. D., \& Krajewski, W. F. (2009). Flood frequency analysis for nonstationary annual peak records in an urban drainage basin. Advances in Water Resources, 32(8), 1255-1266. https://doi.org/10.1016/j.advwatres.2009.05.003

Vlotman, W. F., Wong, T., \& Schultz, B. (2007). INTEGRATION OF DRAINAGE, WATER QUALITY AND FLOOD MANAGEMENT IN RURAL, URBAN AND LOWLAND AREAS. Irrigation and Drainage, 56, s161-s177. https://doi.org/10.1002/ird.369

Wei, C. C., Hsu, N. S., \& Huang, C. L. (2014). Two-Stage Pumping Control Model for Flood Mitigation in Inundated Urban Drainage Basins. Water Resources Management, 28(2), 425-444. https://doi.org/10.1007/s11269-013-0491-0

Zhou, Q. (2014). A Review of Sustainable Urban Drainage Systems Considering the Climate Change and Urbanization Impacts. Water, 6(4), 976-992. https://doi.org/10.3390/w6040976

Zhou, W. (2007). Drainage and flooding in karst terranes. Environmental Geology, 51(6), 963-973. https://doi.org/10.1007/s00254-006-0365-3

Zhou, Y., Guo, Y., \& Baetz, B. W. (2016). Underestimation of flood quantiles from parallel drainage areas. Urban Water Journal, 13(5), 441-453. https://doi.org/10.1080/1573062X.2014.993992

\footnotetext{
*corresponding author, Tel: +251910376266
}

Email address: manaye.teshome@gmail.com 